\title{
From bacteria to Saint Francis to Gaia in the symbiotic view of evolution
}

\author{
Massimo Debernardi and Emanuele Serrelli ${ }^{*}$
}

Keywords: Symbiogenesis, Symbiosis, Micro-organisms, Consciousness, Self, Gaia, Lynn Margulis, Evolution,

Unification, Ecology

Chimeras and Consciousness. Evolution of the Sensory Self, eds. by Lynn Margulis, Celeste A. Asikainen, and Wolfgang E. Krumbein. Cambridge, Massachussets and London, England: The MIT Press, 2011. Pp. xviii + 321. $\mathrm{P} / \mathrm{b} \$ 29.00$.

Chimeras and Consciousness is a collection of essays coming mainly from an international conference held in 2004 in Bellagio, Italy, hosted by the Rockefeller Foundation.

Lynn Margulis is the first of the three editors. She hardly needs an introduction: in the late 1960s, she pioneered and forcefully pushed the symbiogenetic theory of the eukaryotic cell (Sagan 1967; Margulis 1970), revolutionary at that time, but today confirmed by an overwhelming mass of researches and data, renewed and deepened at the molecular level in the genomic era (Margulis \& Sagan 2003) $)^{\mathrm{a}}$. Eukaryotes have originated by repeated symbiogenesis, the most famous of which is the incorporation of former free-living bacteria (Lane \& Martin 2010). Details of the sequence and mechanisms of the Serial Endosymbiosis Theory (SET) are still today an exciting field of research (for example, Sassera et al. 2011). Margulis is unanimously seen as the scientist who opened this new field of research. She is also known for her tendency to radicalize and generalize her views against the established ones, being a forerunner not only for some specific theories but also for a way of looking to the living world based on symbiosis and association (cf. Gontier 2007, O’Malley 2010).

Second editor of Chimeras and Consciousness is Celeste A. Asikainen, a young geologist, student in geosciences at Lynn's same institution: the University of

\footnotetext{
* Correspondence: emanuele.serrelli@unimib.it

"Riccardo Massa" Department of Human Sciences, University of Milan Bicocca, Piazza dell'Ateneo Nuovo 1, 20126 Milan, Italy
}

Massachussets, Amherst. Last editor is Wolfgang E. Krumbein, geomicrobiologist at the Institut für Chemie und Biologie des Meeres, Carl Von Ossietzky Universität, Oldenburg, Germany. We received the book to review for Evolution: Education and Outreach in October 2011. One month later, on November 22, Lynn Margulis died unexpectedly at 73 . We hope that Asikainen and Krumbein will not feel downplayed if we try to interpret Chimeras and Consciousness mainly in the light of Lynn's lifetime work.

In the section 'What's in Chimeras and Consciousness' we summarize the content of the 23 essays appearing in the book organized in five parts: 'Selves', 'Groups', 'Earth', 'Chimeras', and 'Consciousness'. We also make a few comments on such a structure, probing both the boundaries and internal coherence of these topics. The main goal of the book seems a kind of innovative unification of entities and processes like consciousness, micro-organisms, evolution, and the chemico-physical processes involving the Earth as a whole. The editors and authors want to break up with a tradition that, in their view, keeps all these topics separated and marginalize some of them, thus hindering understanding. Then we assess this unifiying endeavor, analyzing it in terms of an all-encompassing glance, of the discovery of sameness, and/or of an explanatory history or theory. The conclusion summarizes and makes an overall evaluation of the book as more an inspirational than a scientific work, related to some ancient philosophical themes.

\section{What's in Chimeras and Consciousness}

The longest parts in the book are on chimeras (seven essays) and consciousness (five essays). The shortest is the one about Earth (three essays). In what follows we 
try to indicate the specialization of every author for two reasons: first we want to appreciate the remarkable interdisciplinarity of the group; second we want to assess a claim made by Lynn Margulis in the Preface, characterizing the authors as 'real scientists' as opposed to intermediaries or journalists (see 'Unification as a putative causal story' below).

The first part, 'Selves', is about micro-organisms seen as the most basic example of what a self is. Actually, the first essay by medical researcher Frank P. Ryan (Ch.1) is about viruses and claims that they are not selves, and the second by chemist William Day (Ch.2) is about the origin of life, that is on the transition between living and non-living. So we may say that the first half of the section is devoted to probe the fuzzy boundaries of the category of 'self', where viruses are an important although non-autonomous element:

...the "selves" of viruses, utterly depend on their physical contact with bacterial or other living cells. If not connected to a cell, a virus is as inert as a lump of salt or a cube of sugar. The basic element of life, the self, is the sensitive bacterial cell; but a virus, as a courier and an integrator of genes into bacteria and nucleated organisms (animals, plants, fungi and proctotists), can be very important to specific evolutionary trajectories (p. 17).

The second half of Part I presents bacteria as 'social' selves, ever forming communities: chemical signals like alarmones addressed by biologists Antonio Lazcano, Arturo Becerra, and Luis Delaye (Ch.3), analogous to plant and animal hormones, connect and shape such communities, and these in turn alter dramatically their abiotic environment as geobiologist Kenneth $\mathrm{H}$. Nealson describes (Ch.4). A message here is that there is nothing between 'non-living' and 'selves-in-community'. In other words, the editors and perhaps the authors of this book are against the idea of a self in isolation. Sticking to a strict logic of the book, however, it is not clear whether Lazcano et al. and Nealson would have been likewise appropriate in the subsequent part of the book: are the 'communities' described here different from the 'groups' referred to later?

The second part deals with 'Groups', identified as 'life's components' by the editors (p. 5) in opposition to individuals. The chapter by physicist Eshel Ben-Jacob, science manager Yoash Shapira, and philosopher of medicine Alfred I. Tauber (Ch.5) describes bacteria as capable of communication and even social intelligence. The next essay by two of the editors, geomicrobiologist Krumbein and geologist Asikainen (Ch.6), tells how bacteria build large-scale constructions altering the landscape and their own environment. The next essay, by psychotherapist Laurie Lassiter (Ch.7), strives to extend psychodynamic models to micro-organisms, on seriously questionable epistemological bases as we shall see in 'Unification as statement of sameness'. It is from this essay that we drew St. Francis ${ }^{\mathrm{b}}$ into our title. Geoscientist and science communicator James MacAllister comes next ${ }^{\mathrm{c}}$, with a largely theoretical discussion emphasizing the evolutionary significance of groups which are chimeric, from so-called individuals to symbiotic assemblies up to Gaia, that is, 'the physiological system at the surface of our planet' (p. 6).

Part III, 'Earth', addresses the resonances between life and its physical, cosmic macroenvironment. It begins with an essay by astronomist and 'rational astrologist' Bruce Scofield ${ }^{\mathrm{d}}$ focusing on cyclic, regular rhythms: circadian rhythms realized in biochemical processes and widespread in all life's reigns, photoperiodisms, tidal and lunar rhythms, magnetotaxis, solar cycles. Paul Lowman (geologist) and Nathan Currier (music composer) ${ }^{\mathrm{e}}$ address 'how has Earth kept its oceans' (p. 126), showing the crucial importance of life in global water homeoresis. No oceans without life, no plate tectonics without oceans, no biological evolution without tectonics: the loop is closed. Ecologist Peter Warshall, in one of the longest and best documented essays of the whole book, narrates what he calls the 'photo-biological evolutionary history of the planet' (p. 130), that is 'the story of the planet's photo-environments together with life's photosensory systems' (p. 129). Warshall argues for a theory of cognition (including, recently, the human mind) based on light and color discrimination, rooting such phenomena in his photo-biological story. He maintains that such a story 'explains how life can receive, evaluate and act on only certain wavelengths and frequencies of the electromagnetic spectrum' (p. 129), and contributes to accounting for the human mind. In a nutshell: no mind without light.

Part IV, 'Chimeras', groups seven essays. The reason for some choices in such a grouping is not immediately apparent. It is evident that this book pushes 'chimeras' - 'a mythical beast that blends the parts of real animals' and 'something that represents the successful merger of two or more distinct beings' (p. 4) - as a fundamental phenomenon in life and evolution, but what is to be intended with the term?

One possible meaning is found in the expression 'outside becomes inside', in the essay by geoscientist John L. Hall and Lynn Margulis ${ }^{\mathrm{f}}$ : chimera is a compenetration of bodies. In the history of life, it happened many times when '. . organisms of different kinds lived together until they periodically or permanently merged and covered themselves with exudates, skins, sheaths, or coats made by both partners' (p. 162). In particular they address the case of spirochetes, that is, helically-shaped bacteria now 
stably included in the eukariotic cell (although still found in free-living form as well). In eukaryotes, former spirochetes are co-opted as intracellular structures, motility organs, and sensory cilia. 'The scientific literature they write - abounds with evidence that sensory systems of humans and all other mammals (mechanoreception; photoreception; smell and taste) evolved by redeployment of undulipodia' (p. 163). The transition from outside to inside is crucial in the essay by medical microbiologist and immunologist McFall-Ngai about the immune system $^{\mathrm{g}}$ : she proposes that the simple idea of the immune system as a 'non-self' recognition system should be overcome. Vertebrates and invertebrates, indeed, seem to have different evolved strategies in their interaction with the microbial world:

Invertebrates limit their interaction with microbes to only a few species; i.e., their approach is 'restrictive': to rid themselves of all dare enter. By contrast, an individual vertebrate associates with several microbial communities, each composed of hundreds of distinct individually recognized microbial groups (phylotypes). The vertebrate approach is permissive (p. 205).

Interestingly, McFall-Ngai derives some testable hypotheses about the immune systems of different taxa, and counters the idea of vertebrates as immunologically more advanced. The widespread introduction and establishment of communities into an organism is to be taken into account, according to paleoecologist Jessica Hope Whiteside and science writer Dorion Sagan, also in medicine ${ }^{\mathrm{h}}$ : 'A theoretical emerging practice of medical symbiotics [perhaps opposed to antibiotics!-ed.] would explicitly recognize that health must be seen in the context of microecology (the cell communities in the body) and evolutionary change' (p. 215). Debates about 'chimerization' in medical bioethics would perhaps be different in the mind of these authors who look at the deep chimerical nature of any organism, so that even 'eating is a prelude to endosymbiosis' (p. 217).

'Outside becoming inside' is thus a first, processual, transitional meaning of 'chimera' found in the book. But in several passages of the 'Chimeras' section, another related, more (homeo)static category takes center stage: that of part-whole existence. The processual aspect of something entering into something else is downplayed, for example, when Whiteside \& Sagan observe that 'No organism is impregnable; each functions always as part of a community of superorganisms whose behavior, physiology, and even genetics are in flux' (p. 216). Medical researcher Andrew Maniotis ${ }^{i}$ describes some universally shared basic aspects of DNA packaging, dating back 3,000 million years ago, questioning the idea that chromosomes are separated and independent one from the other. Maniotis's experiments reveal chromosomal discontinuity as an artifact of past experiments: chromosomes are linked by threads of DNA (chromolinkers), a characteristic they share with the ancestral, circular 'genophore', though being augmented and restructured in comparison to it. Another author dealing with chromosomes is geneticist Robin Kolnicki'. She describes chromosome splitting as a mode of speciation that, she argues, occurs in sympatric populations. Evidence of repeated chromosomal splits is found in mammalian evolutionary courses towards specialization. Kolnicki also tries to relate this phenomenon (causing hybrid sterility by genetic incompatibility) with a phenotypic trait which is also important in the evolution of primates: variation of olfactory receptors. For Kolnicki, 'Although there is no evidence that karyotypic fission directly causes genetic and protein changes in primate olfaction, this idea deserves further investigation' (p. 181). For example, Kolnicki speculates, chromosome fission might increase mutation rate in some newly-telomeric regions, so that 'a male's fissioned chromosomes might be sensed' (p. 180). The more general problem Kolnicki seems to be touching is how various kinds of change co-occur and interact in living organisms, whose nature is that of multi-scale aggregates of different entities. Forcing the interpretation a little bit to make some sense of unity of the 'Chimeras' part, all these essays deal with the hierarchical structure of the living, below and above the level of the 'individual'. Inverted commas are due: paradoxically, it seems that the recognition of life's radically chimeric nature forces these authors to question the very idea of 'one individual', ending up by ontologically dissolving chimeras too. No individuals, indeed, implies no chimeras (that is, combined individuals). In its second meaning chimeras is thus an instrumental, disposable critical concept aimed at questioning the notion of neatly defined, isolated living entities. The authors seem to share part-whole descriptions tinged with a 'cosmic' community view pervaded by 'the priority of interactions and interrelationships' (p. 1): for Whiteside and Sagan, for example, 'Clearly a new science, "medical symbiotics", might be organized, planned, and funded that would study health from a cosmic and microecological standpoint. The first task would be to jettison the idealistic nonsense of the organism as an isolated, genetically impregnable system, a culture of one' (p. 218).

Another meaning of chimeras is more markedly genotypic: chimeras are organisms whose DNA includes sequences from different lineages. Viruses, as already seen in essay 1 , are one of the vectors of Lateral Gene Transfers. Sonya E. Vickers and Donald I. Williamson ${ }^{\mathrm{k}}$ present the striking case of invertebrate species sharing identical larval stages, their adult forms being as diverse as a moth and an ant, or a worm and a clam. Excluding both 
common inheritance and phylogenetic convergence, and relying on evidence for recent achievement of a larval stage in many lineages, they follow the larval-transfer hypothesis ${ }^{1}$, proposing that 'an adult animal and its larvae are a chimera that evolved from the fusion of at least two very different animals' (p 185). Vickers and Williamson call for a familiarity with punctuated equilibria theory (Eldredge \& Gould 1972), but they do not remark that their own inference on evolution is stronger, implying saltation within one generation:

Fertile sex - egg-sperm fertilization - occurred (and still does) between members of entirely different species, even different phyla. The rare but fertile hybrids generated striking new animal life forms in a geological instant. [...] Some hybrids, in fact, left many viable descendants that survived as doubled and even tripled or even quadrupled genomes. How did two or more disparate animal beings in the same body at the same time ensure the indefinite continued survival of the hybrids? By expression of the combined genome in sequence rather than concurrently. The larval genome is envisioned to express itself first in the sequence; then the second, third, or fourth genome would express the adult morphology. Metamorphosis from larva to adult is a legacy of the shift from one to another of unlike ancestors (pp. 183-4).

A further meaning of chimera seems to be proposed in part V by neuroscientist John Skoyles ${ }^{\mathrm{m}}$. He argues that the human brain is 'chimerized' in that symbols 'blend' with its neural apparatus, modifying its functioning. This is possible because evolution left areas of the cortex open to training and retraining, thus allowing for ontogenic neural plasticity. Skolyles's favorite examples concern experiments showing that the auditory cortex receiving light in early development can visually recognize objects, and, vice versa, the visual cortex can develop and become auditory. 'Spare cerebral cortex' is also necessary to plasticity: 'the symbol processing [...] requires a large brain so newly developed functions will not crowd out old ones' (p. 236). Symbols, for Skoyles, chimerize neural circuits 'by providing them with novel inputs and outputs' (p. 239). Notice that chimerization, in this case, is something being reliably repeated in each generation, individual by individual, during development and learning. Language, for example, 'depends on ancestors [...]. Alreadyexisting input is essential. Language doesn't emerge de novo in each person; it is passed, with little modification, from generation to generation. We speak the language of our parents, they spoke the language of their parents, and so on, further and further back in the past' (p. 236).
The evolutionary hypothesis in this view is that, before the invention of symbols in human evolution, brains 'were raw perceptions, motor control, and emotions that were just sufficiently developed to enable continued animal survival. But now chimerized, they generate a rich diversity of attributes that had not existed previously' (p. 238).

Part V is dedicated to Consciousness. Skoyles's proposal of the brain-symbols chimera (seen above) might seem at odds with other notions involving the combination of living beings (symbols are not), or, at least, material transfer. Science writer Dorion Sagan ${ }^{\mathrm{n}}$ can be seen as casting a bridge here, by showing that cultural objects involve energy-matter transfer as well. He questions the traditional 'mind-matter' divide exploring its philosophical roots, and arguing that 'consciousness, far from belonging to a radically distinct "spiritual" realm, is an outgrowth of the naturally complex behavior of selfmaintaining thermodynamic systems' (p. 250). Primatologist Judith Masters ${ }^{\circ}$ describes how jungle primates (great galagos) maintain social bonds before and beyond copulation and mating, through complex signals that encode for both species and individual identity. In the closing essay, Luis Rico ${ }^{\mathrm{p}}$, artist and culture activist, denounces the fragmentation of knowledge affecting science and art. He admires 'holistic thinkers' (p. 261) comparing, for example, Gaia theory to Dadaism and Futurism (p. 263) in that they seek a message of hope for our future. We are a 'thinking layer' on planet Earth, and 'In spite of our limited, ancient sensory system, our anthropocentrism, prejudical symbolism, biased educations, dangerous ignorance, and distracting technologies, our imaginations tend to soar' (p. 266).

Two appendices and a glossary complement the book. Appendix A lists the major groups of living organisms (from Margulis \& Chapman 2010), and Appendix B shows the International Geological Scale. The 23-page glossary, ranging from 'abiotic' to 'Xanthophyte', is very complete.

\section{An assessment of unificationist achievements of Chimeras and Consciousness}

At the beginning of this review we identified innovative unification as a main goal of Chimeras and Consciousness. According to Margulis's Preface, science is a specialistic detailed exploration that tends to lose the big picture, despite the fact that nature disregards boundaries among disciplines. Fields must be merged and


nalistic complete explanations and comprehensive stories' (p. xiv). Did the editors, by assembling the 23 heterogeneous essays, succeed in realizing, or at least in paving the way for, a scientific unification of glaringly distant terms like evolution, selves, groups, the Earth, chimeras, and consciousness? The answer varies according to the 
meaning given to 'unification'. The book seems to mildly succeed in bringing together those phenomena in a grand picture, a fresco with significant changes of focus with respect to usual ways to pose the problems. But, if by unification we mean a grand empirical hypothesis, a 'unified account of a range of different phenomena [that] may exhibit connections or relationships between phenomena previously thought to be unrelated' (Woodward 2009), Chimeras and Consciousness seems to be ashore. Abstraction from phenomena like symbiogenesis or communication among bacteria leads to unifications that risk to be only terminological, and to overlook important distinctions, for example, purpose $v s$. equilibrium, or ecological vs. genealogical assemblies. For what concerns correlations and descent among, for example, conciousness, self, evolution, and cosmic processes, the book leaves us with scarce general hypotheses. Least of all it answers 'the greatest mystery', that is, the origin and evolution of life's consciousness from the simple behaviors and interrelationships of connected living entities (Margulis on p. xiv).

\section{Unification as looking together}

First, consider unification as a kind of 'looking together' things that are usually viewed separately and of shifting scientific attention towards less explored territories. Lynn Margulis has been described as 'the microcosm champion' (Bandi \& Casiraghi 2011). She thought that evolutionary biologists had been shortsighted in narrowing down evolution to metazoans, that is, to the last 500 millions of years over more than 3.5 billion (the time passed since the origin of life). Microbes dominate at all scales, their scientific study does not. For example, 'Ten percent or more of our body weight - Margulis said - is bacterial, and it's just foolish to ignore that' (in Mann 1991, p. 378). In about a half of Chimeras and Consciousness (for example, 3, 4, 5, 6, 8, 13, 18) bacteria and other micro-organisms have a leading role. In his essay, James MacAllister writes:

The zoological view that dominates the literature on evolution is short-sighted. S.J. Gould once characterized the Precambrian as a time in which "nothing happened for ever so long". "On the contrary" the evolutionist Lynn Margulis replied "the Precambrian is when everything important in the evolution of life is happened" (p. 103).

Today the scientific milieu is friendly to this approach, and the idea that microbes are the dominant life form on the planet, both now and throughout evolutionary history' (O'Malley \& Dupré 2007, p. 155) is more widely accepted. Furthermore, a growing literature argues that microbes, differing from macrobes by a number of crucial aspects, have the potentiality of revolutionizing the scientific view of evolution, for example undermining the classic idea of the tree of life (O'Malley 2010). By the way, the apology of microbes is both contradicted and reaffirmed by the cover illustration of Chimeras and Consciousness, dominated by the photograph of a fluffy lemur, with the humble and marginal superimposition of a few, small, drawn proctists and microscopic images. The cover contradicts the book's spirit, but at the same time reveals the 'mammalian attraction' of potential readers, reaffirming the still current necessity of fighting for microbes. Margulis's lifetime effort could be described as a double, 'zooming out-zooming in' movement: it is the consideration of the '3-billion-year dance between life and the environment' (Eldredge in Mann 1991, p. 381) that brings into clear focus the pre-eminence of micro-organisms. The same movement can be perceived in Chimeras and Consciousness, especially in Part III: in reading the essays therein, one gets a picture of the large-scale, cosmic, dynamic physico-chemical systems that encapsulate life on Earth. From this standpoint, micro-organisms take a massive part in huge waves of light ${ }^{\mathrm{r}}$, matter ${ }^{\mathrm{s}}$, and energy, whereas metazoans (all the most vertebrates, mammals, primates, and us) look like feeble and evanescent foam. Laying down a phenomenon like 'consciousness' in such a context generates a perspective which seems interesting and unusual: a top-down view, in which consciousness is seen as a stroke in the big picture of life, a product of the conditions allowing us to be here. This top-down view may have specific implications for research, like when the editors suggest that the most elemental of all senses might be life's sensitivity to the quantity and the saltiness of water' (pp. 10-13).

\section{Unification as statement of sameness}

In Chimeras and Consciousness a self is an autopoietic unit. Grossly, a unicellular organism is the minimal self (although the origin of life is 'more like a waterfall', essay 2). Yet the book plays on the ambiguity between this relatively undemanding definition of self and the psychological meaning of self, concerned with emotion, cognition, sociality, and representation (for example, Sedikides \& Brewer 2010). Common sense too, after all, relates 'self' to our emotional and rational consciousness and awareness. In the foreword, theologian John Cobbs seems to reveal this unresolved ambiguity when he writes that "we can study the evolution of what in this book are called "selves" as well as the evolution of bodies' (p. $\mathrm{x}$, our emphasis). Would psychologists be satisfied by the redefinition of 'self' - their own object of study (for example, Gallagher 2011) - operated in the book? Conversely, isn't there the risk of projecting and superimposing psychic phenomena on the impertinent domain of unicellular life? Psychotherapist Laurie 
Lassiter, author of essay 7, claims that Murray Bowen's psychodynamic theory of the 'differentiation of the self' (DoS) applies, as it is, 'to microbes, including myxobacteria and heterocystous (nitrogen-fixing) cyanobacteria' (p. 72). In this view, Lassiter performs a series of identifications, for example, the reproductive cells in the filament of heterocysts would be the 'emotional system' of heterocysts (p. 88). More generally, for Lassiter 'Bowen's main idea - that developmental processes in the family emotional system determine individuals' life course trends - [...] is conducive to detailed analysis of individual and group behavior for accurate description of the social lives of not only the human family but also the many other gregarious forms of life' (p. 90). Lassiter's essay seems largely off-line with respect to the biological tone of the preceding essays, so much so indeed to sound grotesque. In our view, while there can be some common pattern in triadic and, more generally, interactive systems, it is far too much to say that the same theory applies to Saint Francis and cyanobacteria ${ }^{t}$.

Chimeras and Consciousness features a series of scattered and parallel terminological choices: statements of sameness. But their unification effect is debatable. The idea of collectively-intelligent bacteria (essay 5), for example, could knock us off our chairs ${ }^{\mathrm{u}}$, but it has to be contextualized in the rethoric strategy of this book, based on an often implicit redefinition of terms. This redefinition in fact cannot satisfy someone who is looking for 'what's peculiar about animal or human intelligence': if we normalize intelligence, we lose our explanandum. Even the crucial term 'chimeras' (part IV) is, in our view, a terminological aggregation of seemingly heterogeneous entities and processes. As we have already analyzed, different cases of compenetration of bodies, part-whole existence, connectedness, genetic hybridization, and fusional blending don't seem to share a common pattern or mechanism beyond a very general, intuitive idea. So probably what is going on with these terminological unifications is an abstraction from the process of symbiogenesis - a corroborated empirical hypothesis - and a use of it, through the terminological shift to 'chimeras', as a metaphor of many other dynamics in the history of life. Indeed, one thing is to claim that 'evolution by symbiosis or "symbiogenesis" could explain many specific phenomena' (Schaechter 2012), another thing is to argue that symbiosis explains the great majority of biological evolution (marginalizing natural selection), a further claim is that evolution wholesale happens by chimerization. And chimeras as a metaphor become a more and more general view, an epistemological filter that privileges and detects certain features. Such strategy seems, eventually, to mirror the polemic target of the book, that is, neo-Darwinism. Or better, as we read in the foreword by theologian John B. Cobbs, the transfiguration of neo-
Darwinism into a philosophical position, an ideology, namely the commitment to a reductionist, determinist, geno-centric metaphysics (p. ix), and the reductio ad absurdum of living things as 'zombies', machines manipulated by genes seen as 'forces' (p. x). Cobbs also says that the 'zombies account' has done harm 'partly by evoking equally unacceptable reactions' (p. xi). Is Chimeras and Consciousness a scientifically acceptable reaction? Our worry is that the transfiguration of symbiogenesis into a philosophical position hardly brings a surplus of scientific knowledge, while it runs the risk of overlooking some crucial achievements of evolutionary biology, like the reformulation of teleological claims, and the distinction between ecological and genealogical domains, as we explain hereafter.

The 'chimerizing' general view of evolution seems to bring along an inference that reintroduces purpose in evolution. The first premise of the inference is, as Cobb's foreword emphasizes, that the activity of living things is causally relevant and explanatory of what happens; in opposition, genetic mutations often follow on changed behavior: 'the accumulation of random mutations in genes - the editors write in the introduction - is neither the only source of evolutionary novelty nor the major sources' (p. 3). The second premise is that animal activity is mostly purposeful. The deduction would be that we are allowed to talk about evolution in genuinely finalistic terms, as suggested by expressions like 'life changes the environment to fit itself' (p. 13), or 'endosymbiosis [which precedes both plants and animals] altered Earth by providing plants for animals to eat and additional oxygen for them to breathe' (Lake 2012). The evident error of reasoning here is that goal-directedness is very hardly preserved in spatio-temporal scale transitions. Darwin's theory of natural selection expunged purpose from the history of life by the principle of blind variation and selective retention. Blind variation does not mean that individual organisms are blind or dumb: it might well be the contrary. But variation is blind to its cumulative, large-scale effects. This crucial passage in evolutionary theory, which has to do with scale shifting, is perhaps difficult to grasp and hold. From time to time, theoretical innovations are misinterpreted as if they would reintroduce purpose in evolution. A recent case shows some receptions of niche construction theory, where the aggregate, long-term impact of population's characteristics on selective pressures has been conflated with an individual organism's purposeful modification of its immediate environment (for example, Laland et al. 2009). At times, Chimeras and Consciousness seems to lean towards similar, mistaken implications:

- having an evolved and regulated role in the homeostasis of Gaia (granted that the latter is an 
autopoietic system, see below) is identified with having a community-oriented nature and actionpattern, whereas there is no reason to rule out that Gaia's large scale equilibrium could be compatible with various local-scale action and relationship patterns, including non-cooperative and 'selfish' ones;

- being in an ancestral phylogenetic position, bacteria are seen as a passage in a suggested tendency to change and evolve more and more complex kinds of awareness $^{\mathrm{v}}$, whereas there is no such internal linear tendency to complexity in evolution, and projection of later outcomes on evolutionary precursors conveys an appearance of predestination and determinism;

- similarly, looking at symbiotic associations as if they only result from an internal élan neglects the fact that they are here because they worked (and there is no necessary ethical burden on this part of the mechanism, which by the way has the virtue of explaining cases where associations do not happen or do not work so well).

So the reintroduction of purpose in evolution seems to result from amnesia about the laws of scale-shifting, known and crucial in evolutionary theory. Another oversight concerns the fact that ecological groups do not coincide with evolutionary groups, and more generally the economic and the genealogical domains are distinct although related in the living world (Eldredge 2008). Chimeras and Consciousness insists that individual survival is not the only dynamics: collectivities and associations act in evolution (p. 3).

Neo-Darwinists tend to ignore any ecological concept of community and deny the idea that communities can be identified as units that evolve (MacAllister, p. 98).

But the book is never explicit about the fact that action in evolution has to do with - and only with - producing lineages. Collectivities and associations are ecological assemblies that act in the ecological-economic world, in a sensory and physiological context. They act also in evolution if and to the extent that they impact the configuration of lineages in the genealogical space. Consider the following passage:

As the word "chimera" suggests, all organisms visible to the unaided eye are integrated former symbionts.

Evolving from ancestral units, organisms of different kinds lived together until they periodically or permanently merged and covered themselves with exudates, skins, sheaths, or coats made by both partners. Over evolutionary time, the outside became the inside at a higher, more inclusive level of living organization (p. 162).
This account visualizes these organisms of different kinds in the ecological world doing all these actions during their life, and the dimension of 'evolutionary time' seems to just provide a long, long duration for the effects of these actions to become deep and stable ${ }^{w}$. But being more aware and analytical, we should make explicit that 'over evolutionary time' means shifting from organisms to lineages of organisms, and from environment as a direct agent to environment as a selective agent (on inherited information): so it is inaccurate to say that 'multicellular organisms are integrated former symbionts', rather, back in deep time, the lineage of any multicellular organism gradually splits, traversing a period when the ancestral lineages were merging because somewhere in the ecological world the organisms were living together in close association. Framing things in this way would pretty much soften many polemic claims sounding like 'for neo-Darwinism groups have no role in evolution'. The point is that perhaps ecological aggregations always have effects on genealogy, but such effects are not straightforward. On the other hand, species are certainly the topical example of genealogical unit (closed inbreeding, according to the biological species concept) but they do not play an ecological role: parts of the species - local populations - do. Niles Eldredge has repeatedly and successfully pointed out that ecology and genealogy should not be conflated in evolution. Nonetheless they usually are, and Chimeras and Consciousness does not seem immune to this. Hall and Margulis write, "The word "symbiosis" refers to an ecological condition: the presence of one type of organism becomes the persistent environment of the other' (p. 161, our emphasis). But they omit that this association becomes evolutionarily relevant when there is a merging of lineages (that is, a genealogical condition). And consider this quotation:

Life does indeed change its environment to fit itself [...] does the assertion that "any organism" is "well adapted to its environment" have any meaning? All organisms alive today are "adapted" by virtue of the fact that they live. Their ancestors have survived from the past to the present. Gaia emerges as different organisms affect one another and their surroundings (p. 13).

Organisms do indeed alter the environment and affect others in a way that favors their continuing existence, but in fact, while they do so, at the very same time, they do have a differential probability of surviving and reproducing. As Ghiselin (1966) clarified very well, differential reproductive success (fitness) is a statistical measure that nonetheless, through heritability, affects the long term change of populations. 


\section{Unification as a putative causal story}

Finally, consider unification as the proposal of some empirical hypothesis about relationships and descent between selves, symbiosis, consciousness, geochemical processes, and so on. In the Introduction, the editors write: 'Sensitivity, awareness and consciousness correlate with living behaviour, which evolutionarily began with bacteria' (p. 3, our emphasis). They furthermore claim that cell awareness was here from the time of the origin of earliest life, and that awareness and sensation continued to evolve into full-blown consciousness as we humans experience and verbalize it. Several essays suggest that the phenomena they deal with are somehow necessary precursors of consciousness or related issues: Warshall in essay 11 , for example, concludes by saying that the complex ancient photosensitive systems that produce and respond to visible signals became an essential precursor to the human mind' (p. 149). Are there, in Chimeras and Consciousness, hypotheses of how it could happen? Only one essay addresses the issue directly, although briefly: essay 19 by Gerhard Roth. Roth relies on a theory of the states of consciousness, that would be shared through the animal kingdom to different extent. Simple awareness and attention are widely shared, selfreflection allowed by complex language is uniquely human, and in between we have empathy/anticipation (found in primates and cetaceans) and knowledge attribution, self-awareness and language (shared by humans and great apes). Homo sapiens, ça va sans dire, wins all. Moreover, consciousness is distinguished from higher cognitive functions: only some of the latter require the former. There is also a brain comparison among tetrapods, motivated by the fact that, in humans, consciousness seems exclusively associated with the cortex, with some centers shared with animals. The evolutionary hypothesis seems to be an adaptive one for what concerns 'the virtual actor, the ego', where syntactical language played a boosting role:

During the evolution of primates, increases in demands of action planning, strategic thinking, and complex syntactical language probably necessitated the construction of a conscious phenomenal world (p. 228).

Consciousness does not require syntactical language. I posit that, since most people think and plan verbally, the evolution of syntactical language strongly favored higher states of consciousness (p. 231, our emphasis).

Chimeras and Consciousness does collect many empirical hypotheses and theories in specific domains, for example, about working mechanisms of viruses (1), communication among microbes (2), large-scale environmental impacts of bacteria (6), resonances between cosmic and organic rhytms at different levels (9), the cooption of spirochetes as motor and sensory organs in cells (13), the evolutionary sequence in the origin of immune systems (17), the conserved structures of chromosomes (14) and their relation with olfactory reception (15, very speculative), neural plasticity (20), communication among primates (22), and more ${ }^{\mathrm{x}}$. We have to mention that at least two of the theories that are sold in Chimeras and Consciousness do not enjoy much support in the scientific community. This seems at odds with a claim made by Margulis in the Preface, where she calls for scientific authority, specifying that 'unlike popular science "trade books", [this book] is highly concentrated [...] It is "the real thing": the chapters are written by real scientists and other scholars without help [...] the usual intermediaries invariably simplify; with the best of intentions, they try to explain ideas that they do not understand' (p. xiii). We do not know exactly what 'real scientist' is supposed to mean, but in fact there are many science writers and 'free thinkers' among the authors of Chimeras and Consciousness, and most working scientists therein write about topics that are partly outside their specialization. The larval-transfer hypothesis (16), after a communication in PNAS (Williamson 2009) and some harsh criticisms (Borrell 2009), was disproved (Hart \& Grosberg 2009) ${ }^{\mathrm{y}}$; there is no trace of this debate in the book, and that is not really what one would expect from 'real scientists' doing 'the real thing'. The controversial status of the Gaia hypothesis (Introduction, 8, $10,23)^{z}$, first advanced by James Lovelock, is more known. Margulis's commitment to the Gaia hypothesis raised harsh reactions in the scientific community since mid 1970s, as told by Mann (1991): 'many regard autopoietic Gaia as an unscientific attempt to deify the biosphere' (p. 252). Deeming the Gaia hypothesis as unscientific is perhaps exaggerated, given that it could anyway be elaborated so to produce testable predictions (for example, Oduro et al. 2012). But again, the fact that theories and hypotheses in the book are scarcely representative of the scientific community and literature is surprisingly omitted.

\section{Deep philosophical roots}

Should we reconstruct the deep historical genealogy of the inspiration that underlies Chimeras and Consciousness, also taking into consideration the foreword by theologian John Cobb, we think we could call into play terms like Hylozoism, Panpsychism, and above all we should consider Gottfried Wilhelm Leibniz's thought.

Let's start from the notion of Self, which has great importance in the conceptual landscape of Chimeras and 
Consciousness. Theologian John Cobb claims that activity, the foremost feature of living beings, is not to be seen only as reaction to the environment, but it is rather to be understood as ability to carry out an active role in determining what happens. All living beings are active and would be defined selves. As we already pointed out in 'Unification as statement of sameness', the term is not precisely defined, and this leaves - with every probability intentionally - different and even conflicting interpretations open. The word 'self' does not have a clear intension and therefore neither a clear extension. When one, in a very dim way, assigns psychic or mental features even to the simplest living forms, he can be defined as Hylozoist or Panpsychist.

Hylozoism is a term that was coined around the middle of the 17th century by the English theologian and philosopher Ralph Cudworth (1617-1688), one of the most important members of the school of Cambridge.

This school hosted a group of thinkers who shared a common, very syncretistic interest in Plato's philosophy, especially in the thought of philosophers who were members of the Florence Academy (Marsilio Ficino and Pico della Mirandola). Apart from this cultural background, Cambridge philosophers were against Descartes's mechanism, in particular against the extreme mathematical strictness that was basically deterministic. In Descartes's philosophy, matter was understood as totally autonomous from any spiritual agent and this point of view was almost identical to atheism. The term Hylozoism (from Ancient Greek Ǔ $\lambda \eta($ hulē $)=$ matter, and $\zeta \omega \eta ́$ (zōē) = life) stands for the idea that the principle of life is deeply rooted in matter, and forms with this an indissoluble unity. Therefore, matter is no longer understood as an inert and passive principle (cause) receiving action from outside, from a force of different nature. Rather, matter is seen as a dynamic reality in itself.

Panpsychism (from Ancient Greek $\pi \alpha \nu$ (pan) = all, and $\psi u x \eta \dot{~(p s y c h e) ~=~ s o u l) ~ d i f f e r s ~ f r o m ~ H y l o z o i s m, ~ i n s o-~}$ much as it comprises all those doctrines that ascribe to matter an active principle, which is not biological, but spiritual, analogous to the soul.

Hylozoistic positions have been recognized, although controversially, in Thales, Anaximander who saw water as life's principle, giving life to all matter; and also in Anaximander, who could have meant by ' $\alpha$ rा what is not delimited, having no boundaries) an undifferentiated unity of dynamism and action, whence all beings would spring (arise). Besides the Stoics, who saw nature as moved by a vital breathing ( $\pi v \varepsilon \dot{\mu} \mu \alpha)$, hylozoistic positions were very frequent throughout Renaissance. Let's have a look at some of these: Telesio saw the Aristotelic form as an immanent force, an active principle; Bruno imagined matter enlived by a universal force, always creating and diffused in the whole of creation.
The position by the coiner of the term hylozoism, Ralph Cudworth, is especially interesting. He meant to fight atheism in its two different forms, the atomistic mechanistic and the hylozoist. The first, originally put forward by Democritus, admits only the local motion of atoms. The second acknowledges life in nature, without, however, ascribing to it a spiritual nature. Cudworth maintains that the mechanistic view should be integrated with the idea of a nature activated by a plastic or molding force that, according to him, molds matter from within, thus acting as a mediator between the sensible and the intelligible world. In Cudworth's opinion, this molding force is the spiritual tool, unaware of itself, which God would use in order to introduce harmony into the world, to avoid a too immediate interference, consequently being irreproachable of causing evil (Baldi 2006-2010, p. 2456).

In many cases, hylozoism and panpsychism are basically indistinguishable, if we mean by life a sort of animation, as Bruno does. Such overlapping can cause misinterpretations and deep misunderstandings. A philosopher like Leibniz, too, upheld the idea that matter was animated and that it could not be reduced only to atoms provided exclusively with mechanical properties. By getting this idea from Cudworth, Leibniz worked out his theory of the monad. The concept of monad opposes that of atom: if the latter is understood as an inanimate particle, without drive, the former, on the contrary, is conceived as an active principle, that underlies matter and substance, because matter, above all organic matter, is able to act. For Leibniz it was essential to conceive matter on the basis of the notion of soul we have. The monad is labeled in different ways by Leibniz: individual substance, substantial form, real unit, constituent unit, entelechy. It is, after all, a spiritual, active principle, analogous to the soul, and therefore provided with perception, appetition and volition.

The monad gives unity and identity to the body, and appears to be comparable to the soul, that is, to what human beings call the I or Self. As stated above, Leibniz intends to counter monad with atom. Matter, according to him, is not composed of atoms, but of monads, and therefore it should be understood as an aggregate of spiritual substances provided with a self (Boutroux 2001, pp. 43-48). In his most famous work Leibniz writes:

there is a world of created things - living beings, animals, entelechies, souls - in the smallest part of matter.

Each portion of matter can be conceived as like a garden full of plants, or like a pond full of fish. But each branch of a plant, each organ of an animal, each drop of its bodily fluids is also a similar garden or a similar 
pond. And although the earth and the air separating the plants in the garden, or the water separating the fish in the pond, are neither plant nor fish, yet they still contain them - though they are usually far too small for us to be able to perceive them (Leibniz 1720, nn. 66-67-68).

These reflections most likely arose not only from Leibniz's conviction that matter is infinitely divisible, but also, and above all, from the discoveries made by Antonie van Leeuwenhoek (1632-1723). Between 1672 and 1677 the Dutch scientist discovered, thanks to his observations with the microscope, the existence of Protista, bacteria, and spermatozoa, and so he opened the way to microbiology. Leibniz understood that these discoveries would later deeply change the idea of matter as a motionless substrate: it was clear that individual substances existed, that these were animated, provided with a self, and that one could not reduce all to atoms. Notably, hylozoism has been associated with the study of microorganisms since very early in the history of modern science!

To sum up, both the hylozoistic conceptions of matter and Leibniz's ideas about the nature of monad were a reaction against a mechanistic image of the world that was established in the middle of the 17th century, above all through the works of Hobbes and Descartes. Mechanism had expelled final causes from science, and consequently threatened faith in God.

Looking again to Chimeras and Consciousness in light of this sketchy history of ideas, the book gains a very interesting light. By thinking over the notion of self, we can see that deep analogies exist between such notion and Leibniz's idea of monad: it is a matter of centers, unity, and activity. Above all, the polemical aim is shared: if Leibniz and hylozoists like Cudworth entered into a debate against reductionist and basically atheistic mechanism, Lynn Margulis, together with James Lovelock, entered into a debate against a certain kind of gene-centered and reductionist view of Neo-Darwinism.

The foreword of the book by a theologian might imply that the goal of the work is not merely scientific: the symbiogenetic point of view together with the Gaia hypothesis is not only scientific a stance waiting for empirical demonstration. It is, above all, useful. How? Here is what Lovelock wrote about the Gaia hypothesis:

The Gaia hypothesis is for those who like to walk or simply stand and stare, to wonder about the Earth and the life it bears, and to speculate about the consequences of our own presence here. It is an alternative to that pessimistic view which sees nature as a primitive force to be subdued and conquered. It is also an alternative to that equally depressing picture of our planet as a demented spaceship, forever travelling, driverless and purposeless, around an inner circle of the sun (Lovelock 1979, chp. 1, our emphasis).

Gaia and symbiogenesis can tend, perhaps even unconsciously, to reintroduce finalistic explanations. Kant wrote in the Critic of Judgment that a finalistic reflection on the whole universe is just a need of human mind, never to become objective knowledge. Science does not need to think in a finalistic way. We, as human beings, perhaps do.

\section{Conclusion}

Lynn Margulis was member of the US National Academy of Sciences and of the Russian Academy of Natural Sciences, endowed with important awards like the US President's National Medal of Science and the DarwinWallace Medal of the Linnean Society of London (cf. Lake 2012). All colleagues who knew Lynn described her as a bold and strong scientist whose 'success did not come easily. She had to stand up for her ideas and accept repeated rejections' (Lake, cit.). Most accounts tell that many scientists, after Lynn's successful struggle for the endosymbiotic theory, developed a fascinating cautionary attitude towards her ideas. John Maynard Smith, for example, said to Charles Mann:

I think she's often wrong ... But I must say, she was crashingly right once, and many of us thought she was wrong then, too (Ivi, p. 379).

How should the book she edited with Asikainen and Krumbein, Chimeras and Consciousness, be welcomed? An important point is that several kinds of ideas can be found in Margulis's record as well as in this book, and each and every kind of idea can be right or wrong in a peculiar way. Let us review the ideas of unification proposed in the book.

In the case of 'looking together the micro and the macro' ('Unification as looking together'), it does not seem appropriate to ask whether that is 'right or wrong'. A comprehensive, non-compartimentalized look at physics with biology, microbes with macrobes, humans with all living species, genetics with ecological behavior, selection with symbiosis, planet with biosphere, and so on, seems to be legitimate and helping against partiality and towards an appreciation of relative importance. Margulis was always 'crashingly right' in calling for attention on microbes, whereas we all 'generally perceive life to fall into two broad categories, the microbes and macrobes, and then pay most of their attention to the latter' (O'Malley \& Dupré cit.). Yet, it is important to say that this perspective does not automatically explain away human or animal consciousness: in biology, species-specific, 
unique, or rare traits, however small and transitory, need explanation.

As for empirical hypotheses ('Unification as a putative causal story'), by definition they can be true or false, like the SET: as Schaechter (2012) reports, Margulis 'correctly predicted that, if an organelle originated as a free-living cell, it is possible that naturally occurring counterparts still can be found among extant organisms', and that is exactly what happened. Empirical hypotheses yield predictions: difficult and long as it might be to test and decide about it, eukaryotic cells either have or haven't originated by symbiosis; more narrowly, this or that particular genome either is or isn't the result of some hybridation among ancestors. Chimeras and Consciousness reports many hypotheses of this kind. There are two severe limits, however. First, very few of them address the 'really hard problem' in the subtitle - that is, how did the sensory self and consciousness evolve. Second, despite the air of authority exhibited by this MIT Press book, at least some of the particular hypotheses here are controversial in the scientific community, and this is not explicitly addressed nor declared.

The terminological unifications (for example, chimeras, self, intelligence) adopted in Chimeras and Consciousness ('Unification as statement of sameness') seem essentially vague and metaphorical. They play on ambiguities. The SET, the massive lateral gene transfer that happened throughout evolution, and other theoretical and empirical acquisitions undergo abstraction to a certain extent, and together they give a picture of life as 'not shy' (p. 4), forming associations more spontaneously and more easily than previously thought (in the blatantly deprecated, allegedly arid neo-Darwinian framework). These abstractions and identifications might have heuristic value, and build a perspective unveiling new connections and phenomena. They are original ways of organizing what we already know, more than new hypotheses about what we do not know. But they also bring along confusion, particularly by overlooking distinctions like purpose $v s$. equilibrium, predestinate $v s$. prerequisite, and ecological vs. genealogical, and they draw an outdated, linear and progressionist picture of evolution. Moreover, a well-known problem is that works like this can be seen as supporting anti-naturalistic views and apparent compatibilities with supernatural explanatory factors. Often authors are not unaware of these risks, and in reading Chimeras and Consciousness too we have this sensation of a wink to theology.

But Lynn Margulis was an educator. Krumbein, as far as we can infer from available information, is also a raiser of young scholars. And Asikainen is herself one of those young people, scientifically growing mature in a transformed evolutionary theory. Margulis was a patient, bold, and uninhibited educator of minds for her colleagues and the public, pushing them to accept new and better ways of thinking appearing indigestible and counterintuitive in the beginning. In non-public contexts, she revealed that her support towards James Lovelock was less the sharing of Gaia as a scientific hypothesis, than it was a way of diffusing a metaphor potentially increasing people's responsiveness to environmental problems and respect for life and Earth (Bandi \& Casiraghi 2011). Chimeras and Consciousness can be certainly read along such inspirational line. Although affected by a certain lack of scientific focus and coherence, and perhaps not the best form to that aim (would a suggestive, single-authored monograph do the job better?), Chimeras and Consciousness is a new concretion of the illustrious tradition coming from ancient hylozoist thinkers through Leibniz, a tradition struggling with finalistic thinking and challenging mechanism, seen as drifting and - today more than yesterday - hazardous for our future.

\section{Endnotes}

${ }^{a}$ As Schaechter (2012) summarized, 'evolution [...] also occurs by the acquisition of packets of genes simultaneously[...] by acquiring an combining multiple arrays of genes that evolved for different functions [...] bacteria acquire such packets through the incorporation of viruses or plasmids'.

b Cantico di Frate Sole (also known as Canticus or Laudes Creaturarum or Cantico delle Creature) is the most ancient text in Italian literature. It is both a hymn contrasting the demarcation and isolation of the self and a praise about brotherhood going beyond the human species to embrace the whole universe. Particular attention is given to Earth, felt in relation with the Sun and the Moon. Authors see community between Saint Francis of Assisi and Lovelock by virtue of love for our planet considered as a living being. They interpret the Saint's thanksgiving as the awareness of our dependency from all creatures and of the deep connectedness of identities.

${ }^{\mathrm{c}}$ Chapter 8: Nested communities.

${ }^{\mathrm{d}}$ Chapter 9: Cosmic rhythms of life.

e Chapter 10: Life's tectonics.

${ }^{f}$ Chapter 13: From movement to sensation.

${ }^{g}$ Chapter 17: Origins of the immune system.

${ }^{\mathrm{h}}$ Chapter 18: Medical symbiotics.

${ }^{i}$ Chapter 14: Packaging DNA.

${ }^{j}$ Chapter 15: Lemurs and split chromosomes.

${ }^{\mathrm{k}}$ Chapter 16: Interspecies hybrids.

${ }^{1}$ On the serious lack of scientific consensus of the larval-transfer hypothesis see 'Unification as a putative causal story'.

${ }^{\mathrm{m}}$ Chapter 20: Brains and symbols.

${ }^{\mathrm{n}}$ Chapter 21: Thermodynamics and thought. 
${ }^{\circ}$ Chapter 22: "I know who you are, I know where you live".

${ }^{\mathrm{P}}$ Chapter 23: Cultural networks.

${ }^{\mathrm{q}}$ According to an insightful expression by Schaechter (2012), Lynn Margulis was an example of 'science by erudition'.

${ }^{\mathrm{r}}$ Cf. essay 11.

${ }^{s}$ Seen from the point of view of Gaia theory, for example, life's sensitivity to the quantity and saltiness of water may be the most elemental of all senses (cf. Introduction, p. 12).

${ }^{\mathrm{t}}$ Set aside, for now, the fact that a quick identification of Saint Francis's family and the filament of heterocysts leans towards the conflation between ontogeny and phylogeny that we are going to analyze below.

" Another intelligence-related example, in essay 18, is the statement that 'The Internet is becoming a neural net - a self-sensing, proprioceptive superorganismic organ of cyber-intelligence. "Wiring" - the connecting up of member of societies into superorganisms - has been going on for thousands of millions of years, since before the origin of eukaryotic cells' (p. 213).

$v$ 'Sensitivity, awareness and consciousness correlate with living behaviour, which evolutionarily began with bacteria... Cell awareness was here from the time of the origin of earliest life. Awareness and sensation continued to evolve into full-blown consciousness as we humans experience and verbalize it' (p. 3).

w The same impression comes from Mann (1991) when he recounts Margulis's view that 'the unit of biological study is not the individual but the symbiotic system, which is primarily characterized by the property of "autopoiesis"' (p. 379).

${ }^{x}$ Empirical hypotheses can also be hypotheses about absence: for example, no living beings exist in isolation $(2,18)$.

$\mathrm{y}$ 'Williamson has made a series of predictions arising from his hypothesis and urged genomicists to test them. Here, we use data already in the literature to show these predictions to be false' (Hart \& Grosberg 2009).

${ }^{\mathrm{z}}$ There are arguably several, more or less demanding versions of the hypothesis. In the book, 'Gaia is much more an enormous set of nested communities that together form a single ecosystem than she is any single organism' (p. 6); it 'is a self-starting system with cybernetic tendencies' (p. 93); 'Earth is an open thermodynamic system that runs on an incessant input of energy form the Sun. Energy flow across gradients generates organization and order' (p. 93); 'The biosphere is not equivalent to Gaia. The planetary Gaian system functions as interrelated dynamic life processes' (p. 99); 'Gaia is composed of nested communities with subsystems from biomes to microbial associations' (p. 100); 'Reciprocity is an emergent property of Gaia: life in and between interactive communities shapes the Gaian system, and natural selection shapes and limits the intrinsic tendency of expansion of cells, individuals, communities and ecosystems' (p. 100); it 'produces and removes gases, ions, metals, and organic compounds through the metabolism, growth, and reproduction of an estimated 30 million species [...]. These interactions in aequeous solution lead to modulation of Earth's surface temperature, of acidity and alkalinity, and of the chemically reactive gases of the atmosphere and the hydrosphere' (p. 124). Gaia theory specifically proposes that water regulation emerges from life itself (p. 11).

\section{Competing interests}

The authors declare no competing interests.

\section{Authors' contributions}

The work is the outcome of a common reflection on the reviewed book. ES took particular care of the sections on unification. MD contributed more to the sections "What's in Chimeras and Consciousness" and "Deep philosophical roots". Both authors read and approved the final manuscript.

\section{Acknowledgement}

ES kindly acknowledges support from the John Templeton Foundation in the framework of the 2012/2013 project "Implementing the Extended Synthesis in Evolutionary Biology into the Sociocultural Domain" carried out at the Lisbon Applied Evolutionary Epistemology Lab.

Received: 8 January 2013 Accepted: 8 January 2013

Published: 26 March 2013

\section{References}

Baldi, M. (2006-2010). Cudworth In: Enciclopedia Filosofica, vol. N. Milan, Italy: Bompiani. Bandi, C, \& Casiraghi, M. (2011). Lynn Margulis, la portavoce del microcosmo. Pikaia. http:// unw.pikaia.eu/EasyNe2/Notizie/Lynn_Margulis_la_portavoce_del_microcosmo.aspx. Accessed 19 September 2012.

Borrell, B. (2009). National Academy as National Enquirer? PNAS publishes theory that caterpillars originated from interspecies sex. Scientific American Online, August 24th, 2009, http://www.scientificamerican.com/article.cfm? id=national-academy-as-national-enquirer.

Boutroux, E. (2001). La filosofia di Leibniz. In G Leibniz, La monadologia. Fabbri: Milan, Italy

Eldredge, N. (2008). Hierarchies and the sloshing bucket: toward the unification of evolutionary biology. Evolution: Education \& Outreach, 1(1), 10-15.

Eldredge, N, \& Gould, SJ. (1972). Punctuated equilibria: an alternative to phyletic gradualism. In TJM Schopf (Ed.) Models in paleobiology. San Francisco: Freeman Cooper and Co., 82-115.

Gallagher, S (Ed.). (2011). The Oxford Handbook of the Self. Oxford: Oxford University Press.

Ghiselin, MT. (1966). On semantic pitfalls of biological adaptation. Philosophy of Science, 33, 147-153.

Gontier, N. (2007). Universal symbiogenesis: An alternative to universal selectionist accounts of evolution. Symbiosis, 44, 167-181.

Hart, MW, \& Grosberg RK. (2009). Caterpillars did not evolve from onychophorans by hybridogenesis. PNAS 106, 19906-19909.

Lake, JA. (2012). Lynn Margulis (1938-2011). Biologist who revolutionized our view of early cell evolution. Nature, 480, 458.

Laland, KN, Odling-Smee, J, Feldman, MW, \& Kendal, J. (2009). Conceptual barriers to progress within evolutionary biology. Foundations of Science, 14(3), 195-216.

Leibniz, G. (1720). Le Principes de la Philosophie, known as The Mondadology.

Lane, N, \& Martin, W. (2010). The energetics of genome complexity. Nature, 467, 929-934.

Lovelock, JE. (1979). Gaia: A New Look at Life on Earth. Oxford: Oxford University Press.

Mann, C. (1991). Lynn Margulis: science's unruly Earth mother. Science, 252, 378-381.

Margulis, L. (1970). Origin of Eukaryotic Cells. New Haven, CT: Yale University Press. 
Margulis, L, \& Chapman, MJ. (2010). Kingdoms and Domains: An Illustrated Guide to the Phyla of Life on Earth (4th ed.). Amsterdam: Academic Press/Elsevier.

Margulis, L, \& Sagan, D. (2003). Acquiring Genomes: A Theory of the Origins of the Species. New York, NY: Basic Books.

Oduro, H, Van Alstyne, KL, \& Farquhar, J. (2012). Sulfur isotope variability of oceanic DMSP generation and its contributions to marine biogenic sulfur emissions. Proceedings of the National Academy of Sciences of the United States of America. doi:10.1073/pnas.1117691109.

O'Malley, MA. (Ed.) (2010). Special issue on the tree of life (15 papers). Biology and Philosophy, 25(4).

O'Malley, MA, \& Dupré, J. (2007). Size doesn't matter: towards a more inclusive philosophy of biology. Biology and Philosophy, 22(2), 155-191.

Sagan, L. (1967). On the origin of mitosing cells. Journal of Theoretical Biology, 14(3), 255-274.

Sassera, D, Lo, N, Epis, S, D'Auria, G, Montagna, M, Comandatore, F, Horner, D, Pereto, J, Luciano, M, Franciosi, F, Ferri, E, Crotti, E, Bazzocchi, C, Daffonchio, D, Sacchi, L, Moya, A, Latorre, A, \& Bandi, C. (2011). Phylogenomic evidence for the presence of a flagellum and cbb3 oxidase in the free-living mitochondrial ancestor. Molecular and Biological Evolution, 28(12), 3285-3296.

Schaechter, M. (2012). Lynn Margulis (1938-2011). Science, 335, 302.

Sedikides, C, \& Brewer, MB. (2010). Individual Self, Relational Self, Collective Self. UK: Psychology Press/Taylor and Francis.

Williamson, DI. (2009). Caterpillars evolved from onychophorans by hybridogenesis. Proceedings of the National Academy of Sciences of the United States of America, 106(47), 19901-19905.

Woodward, J. (2009). Scientific explanation. In EN Zalta (Ed.), The Stanford Encyclopedia of Philosophy (Winter 2011th ed.). http://plato.stanford.edu/ archives/win2011/entries/scientific-explanation/. Accessed 19 September 2012.

doi:10.1186/1936-6434-6-4

Cite this article as: Serrelli and Debernardi: From bacteria to Saint

Francis to Gaia in the symbiotic view of evolution. Evolution: Education and Outreach 2013 6:4.

\section{Submit your manuscript to a SpringerOpen ${ }^{\circ}$ journal and benefit from:}

- Convenient online submission

- Rigorous peer review

- Immediate publication on acceptance

- Open access: articles freely available online

- High visibility within the field

- Retaining the copyright to your article

Submit your next manuscript at $\gg$ springeropen.com 